Revue d'histoire de l'Amérique française

ZAS REVUE D.HISTOIRE DE L'AMÉRIQUE FRANÇAISE

\title{
Les vingt-cinq ans de la Revue d'histoire de l'Amérique française
}

\section{Rosario Bilodeau}

Volume 25, numéro 4, mars 1972

URI : https://id.erudit.org/iderudit/018566ar

DOI : https://doi.org/10.7202/018566ar

Aller au sommaire du numéro

Éditeur(s)

Institut d'histoire de l'Amérique française

ISSN

0035-2357 (imprimé)

1492-1383 (numérique)

Découvrir la revue

Citer ce document

Bilodeau, R. (1972). Les vingt-cinq ans de la Revue d'histoire de l'Amérique française. Revue d'histoire de l'Amérique française, 25(4), 463-464.

https://doi.org/10.7202/018566ar d'utilisation que vous pouvez consulter en ligne.

https://apropos.erudit.org/fr/usagers/politique-dutilisation/ 


\section{Les vingt-cinq ans de la}

\section{REVUE D'HISTOIRE}

\section{DE L'AMÉRIQUE FRANÇAISE}

La Revue termine avec ce numéro son vingt-cinquième volume d'articles, de notes, de comptes rendus, au service de I'histoire de l'Amérique française. Dans les pages liminaires qu'il écrivait dans le premier numéro, en juin 1947, le fondateur de la revue, le chanoine Lionel Groulx, exprimait ainsi l'objectif qu'il entendait poursuivre: "La première nation de l'Europe, première par la supériorité politique et militaire, et première surtout par l'esprit, ne pouvait coloniser comme les autres, imprimer au visage de l'Amérique la même effigie que les autres. Le fait fran gais, par ce qu'il a été et par ce qu'il reste, forme donc un bloù historique à part, un fait de civilisation de caractère original. Ressaisir ce fait en ses traits communs, comme en ses diverses expressions historiques, le ressaisir surtout en son originalité, ainsi que l'on rajusterait ensemble les ossements épars d'un grand mort, l'œuvre nous a paru en valoir la peine. Oeuvre si vaste toutefois que seules la peuvent mener à bien des équipes d'historiens entraînées à travailler chacune sur son terrain, à s'entr'aider dans leurs recherches, à synthétiser leurs travaux par l'action d'un organisme central."

Ce rôle d'organisme central, de lieu de réunion des chercheurs et des historiens, la Revue l'a toujours tenu pour primordial. Dix ans plus tard, on remarquait déjà que les articles de fond dont se composaient les neuf premiers volumes étaient dus 
â quatre-vingt-quinze historiens différents dont les trois quarts étaient du Canada français. Dans un prochain numéro, un dénombrement plus détaillé fera voir encore une fois le nombre et la variété des historiens qui ont pu faire connaître leurs travaux grâce à la Revue.

Pendant ces vingt-cinq ans, la Revue a été ouverte à tous les collaborateurs. Les seuls critères ont été l'objectivité et la qualité. Ici encore, cette attitude a été conforme aux desseins du fondateur qui écrivait dans le deuxième numéro : "Il faut qu'on le sache : l'œuvre entreprise ici n'est pas l'œuvre de quelques hommes, d'un groupe fermé, si large soit-it. Elle n'a pas été fondée pour exprimer les idées ni pour servir les fins d'un groupe. Elle est née pour se mettre au service de toute l'Amérique française, pour en étudier et pour en écrire l'histoire." Ainsi, la Revue a été et demeure le lieu d'accueil de toutes les diversités, pourvu seulement qu'elles se présentent sous les traits de l'objectivité, de l'honnêteté et d'une qualité littéraire suffisante, et qu'elles suscitent une saine inquiétude, une recherche jamais terminée, une interrogation toujours harcelante.

ROSARIO BILODEAU

directeur 